\title{
Effect of Fentanyl with Lidocaine on Hemodynamical Stability of Patients with History of Hypertension in TURP Surgery: A Double Blind Controlled Clinical Trial
}

\author{
Saheban Maleki M.1 MD, Kianmehr M.. ${ }^{2}$ PhD, Talaei A.R.* MSc, Moaven Saeidi Noghabi M.. ${ }^{3}$ MD \\ *15th of Khordad Hospital, Gonabad University of Medical Science, Gonabad, Iran \\ ${ }^{1}$ Anesthesiology Department, Medicine Faculty, Gonabad University of Medical Sciences, Gonabad, Iran \\ 2Medical Physics Department, Medicine School, Gonabad University of Medical Sciences, Gonabad, Iran \\ ${ }^{3} 0$ ccupational Medicine Department, Gonabad University of Medical Science, Gonabad, Iran
}

\begin{abstract}
Aims: Some severe hemodynamic changes are known as problems due to $5 \%$ lidocaine spinal anesthesia at the elderly. Such changes, also, may lead to the cardio-vascular or renal problems. The aim of this study was to compare between the hemodynamic changes in two spinal-cord anesthesia methods with 5\% lidocaine (the current method) and with low 5\% lidocaine dose with $50 \mu \mathrm{g}$ fentanyl in the elderly patients with a systemic blood-pressure increase history in the transurethral resection of the prostate (TURP).

Materials \& Methods: In the two-blinded clinical trial, 148 patients aged more than 50 years with benign prostate hypertrophy, who had referred to $15^{\text {th }}$ of Khordad Hospital of Gonabad for TURP between 2011 and 2012, were studied. The subjects, selected via simple random sampling method, were randomly divided into two groups ( $n=74$ per group). The first and the second groups underwent spinal-cord anesthesia with the administrations of $5 \%$ lidocaine (2cc; 100mg) and 5\% lidocaine (1cc; 50mg) + fentanyl (1cc; 50 $\mathrm{gg}$ ), respectively. Blood-pressure and heart-rate were recorded immediately after the anesthesia and at every 5 minutes. Data was analyzed by SPSS 21 software using independent T and Fisher's exact tests.

Findings: Mean reductions in the systolic and the diastolic blood-pressures $(\mathrm{p}<0.001)$ and mean reduction in the heart-rate $(\mathrm{p}=0.009)$ in lidocaine+fentanyl group were significantly lower than lidocaine group. In lidocaine group, ephedrine and atropine administrations were required in 26 and 19 patients, respectively. Nevertheless, no administration either of ephedrine or of atropine was required in lidocaine + fentanyl group $(p<0.001)$. Conclusion: Without any hemodynamic instability, low lidocaine dose (50mg) with fentanyl $(50 \mu \mathrm{g})$ may result in sufficient anesthesia and no-pain in the elderly patients with a history of controlled high-pressure, who undergo TURP.
\end{abstract}

\section{Keywords}

Spinal Anesthesia [https://www.ncbi.nlm.nih.gov/mesh/68000775]; Hemodynamics [https://www.ncbi.nlm.nih.gov/mesh/68006439];

Lidocaine [https://www.ncbi.nlm.nih.gov/mesh/68008012];

Fentanyl [https://www.ncbi.nlm.nih.gov/mesh/68005283]

* Corresponding Author

Tel: +98 (51) 57251002

Fax: +98 (51) 57231116

Address: $15^{\text {th }}$ of Khordad Hospital, Safa Square, Baydokht, Gonabad

alirezatalaei@yahoo.com

Received: November 21, $2015 \quad$ Accepted: May 10, $2016 \quad$ ePublished: October 1, 2016 


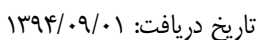

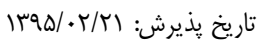

alirezatalaei@yahoo.com :نويسنده مسئول: تاريخ برش:

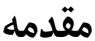

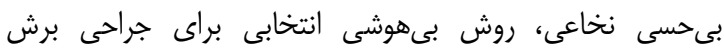

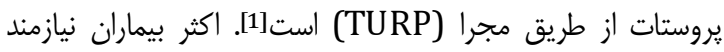
جراحى TURP سالمندند و اغلب دجار بيمارىهاى قلبى و ريوى از جمله يرفشارى خون (فشار خون سيستميك بالا) هستند. بنابراين كاهش عوارض جانبى قلبى - عروقى در اين بيماران مهرم است ح2].

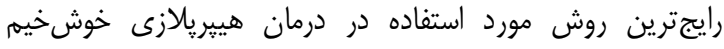
يروستات با حداقل تهاجه، برش ثروستات از طريق مجرا است.

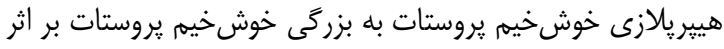

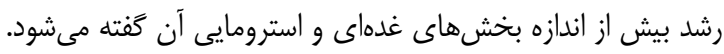
علايم آن ناشى از فشار روى مجراى ادرارى و قطع جريان نرمال

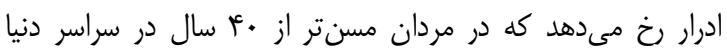

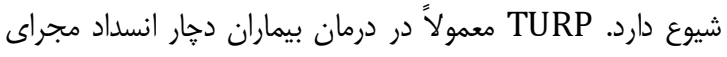

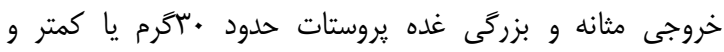
همجنين در افرادى كه محل اوليه انسداد در گردن مثانه است موثر برد است[3].

يكى از مشكلات بى حسى اسپاينال با روش مرسوم يعنى استفاده از

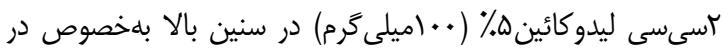
صورت داشتن بيمارىهاى زمينهاى قلبى- عروقى مثل سيل سابقه هييرتانسيون سيستميك، بروز تغييرات شديد هموديناميك بلهورت أفت شديد فشار خون سيستوليك و دياستوليك يا براديكاردى شديد

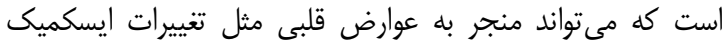
قلبى و حتى كلايس قلبى - عروقى يا عوارض كليوى مثل نكروز حاد توبولر و نارسايى حاد كليه حين و بعد از جراحى شود و بدين طريق باعث افزايش موربيديتى و مورتاليتى بىهوشى اين بيماران

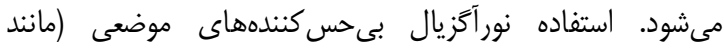

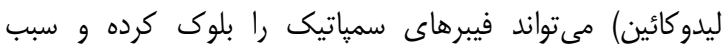

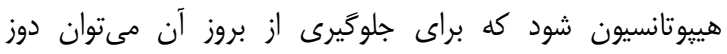

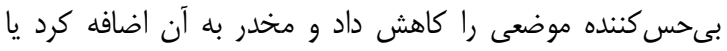
بلهتهايى از مخدر نورآگزيال استفاده كرد، زيرا كاربرد نورآَزيال

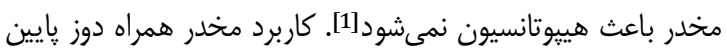

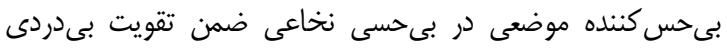

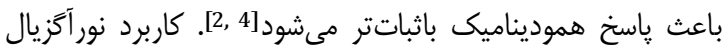

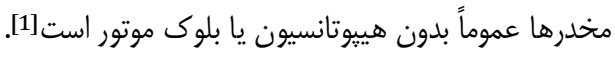

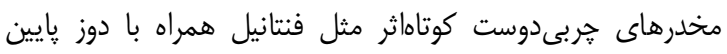

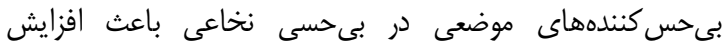

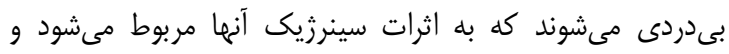
ايجاد بى حسى نخاعى كافى با حداقل اثرات هموديناميك و ورئ
تاثير استفاده از تركيب فنتانيل و ليدوكائين بر ثبات هموديناميك در بى حسى نخاعى بيمار ان باني

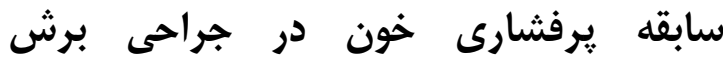
يروستات از طريق مجرا: كارآزمايى بالينى برائ برئ

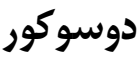

MD محسن صاحبان ملكى

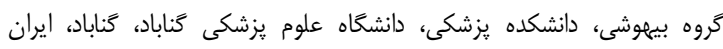

PhD مجتبى كيان مهره كروه فيزيك يزشكى، دانشكده يزشكى، دانشكاه علوم يزشكى كناباد، كناباد،

ايران

MSc علير ضا طلايیى

بيمارستان ها خرداد، دانشخاه علوم يزشكى كناباد، گناباد، ايران MD مريم معاون سعيدى نوقابى كروه طب كار، دانشعاه علوم يزشكى كَابادي، كناباد، ايران

جكيده

الهداف: يكى از مشكلات بىحسى اسِاينال با ليدوكائينه٪ در سنين

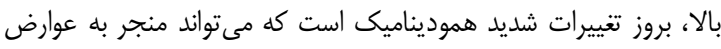
قلبى- عروقى يا كليوى شود. هدف اين مطالعه، مقايسه تغييرات

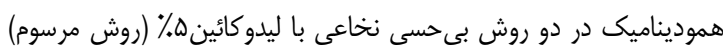

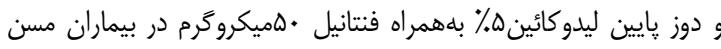

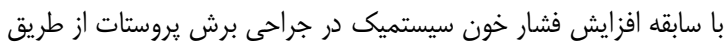
مجرا (TURP) بود.

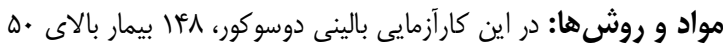

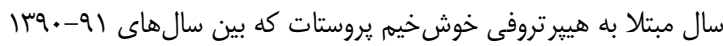

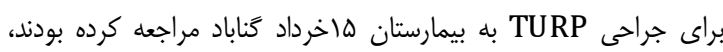

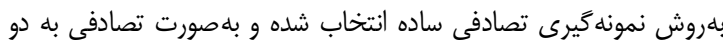

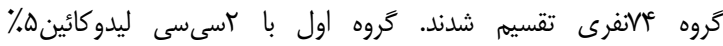

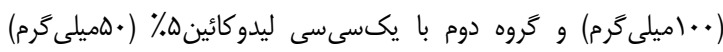

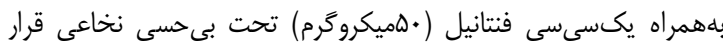

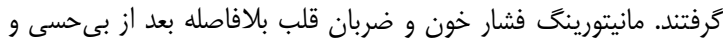

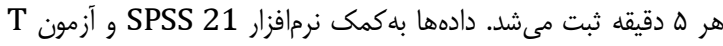
مستقل و آزمون دقيق فيشر تحليل شدند.

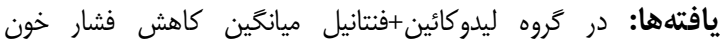

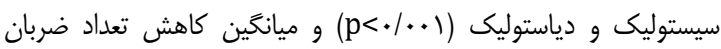

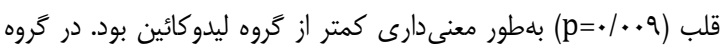

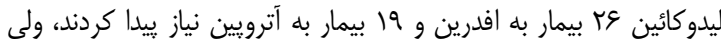

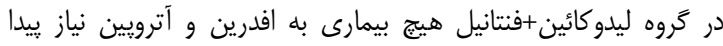
نكرد (1) ( نتيجه كَيرى: دوز يايين ليدوكائين (•مميلى گرم) با فنتانيل •مميكروگرم

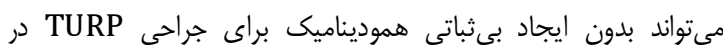

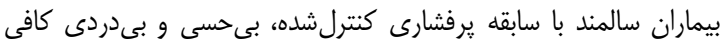
ايجاد كند.

كليدوازهها: بى حسى نخاعى، هموديناميك، ليدوكائين، فنتانيل

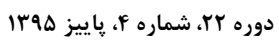

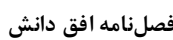




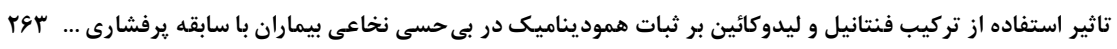

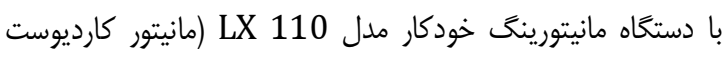

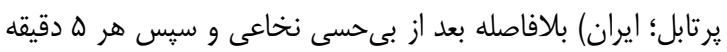

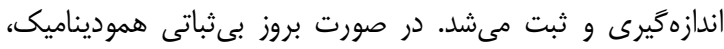

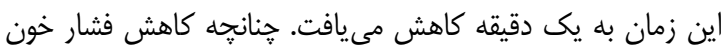

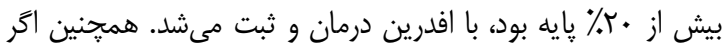

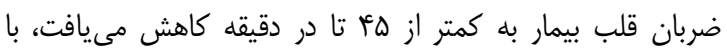

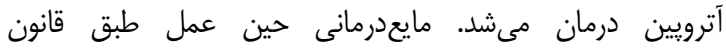

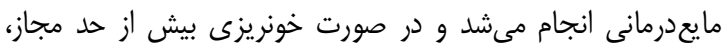

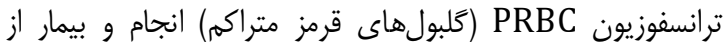

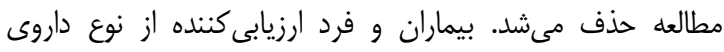
تجويزى ليدوكائين يا ليدوكائين+فنتانيل اطلاع نداشته و مطالعه

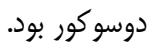

تجزيه و تحليل آمارى اطلاعات جمع آورىشده با كمى نرمافزار SPSS 21

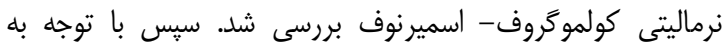

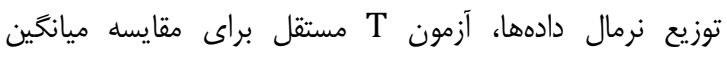

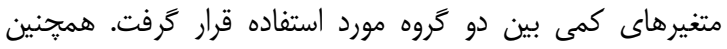
براى بررسى ارتباط بين متغيرهاى كيفى با تروههاى مورد مطالعه از

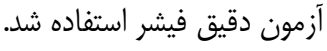

يافتهها

تعداد ^^|| بيمار مورد مطالعه قرار كرفتند و هيج بيمارى از مطالعه

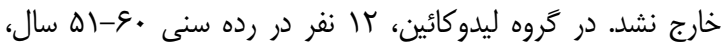

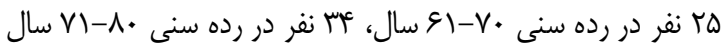

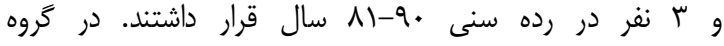

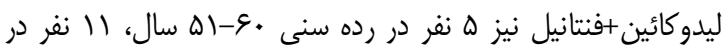

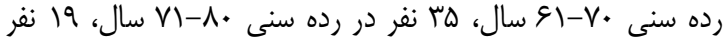

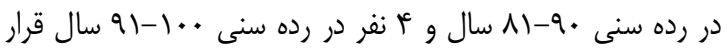
كرفتند.

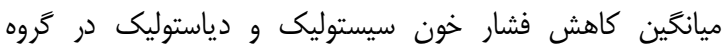

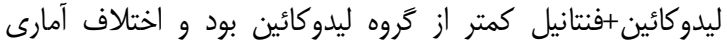

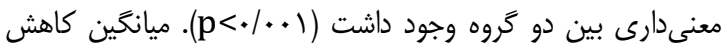

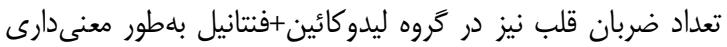

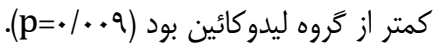

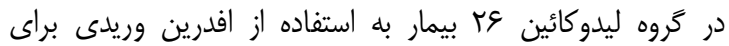

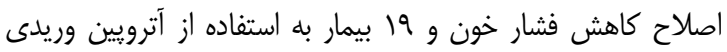

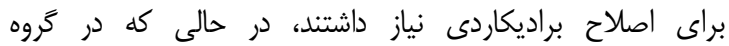

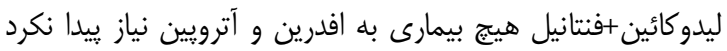
كه از اين نظر بين دو گروه اختلاف آمارى معنى دارى مشاهده شد

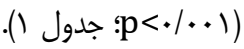
در هر دو گروه، بيماران از كيفيت بىدردى رضايت داشتند و نيازى به فنتانيل وريدى يا بى هوشى عمومى نداشتند.
ريكاورى سريع در جراحى TURP مىنمايد[2]. اين اثر سينرزيك تركي

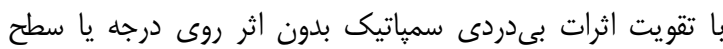

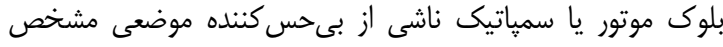

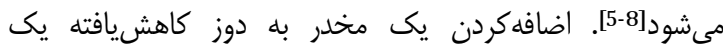
بى بس كننده موضعى در بى حسى نخاعى مى تواند عوارض جانبى

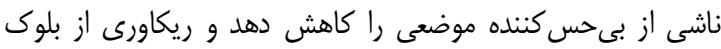

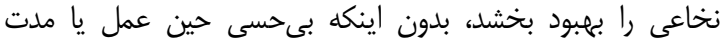

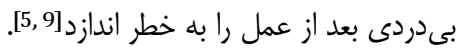
هدف اين مطالعه، مقايسه تغييرات هموديناميك در دور دور روش

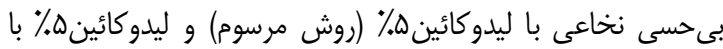

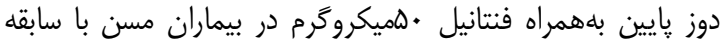

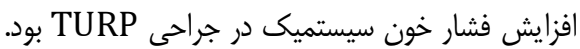

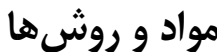

اين يزوهش، يكى كارآزمايى بالينى دوسوكور با كد ثبت كار آزمايى بالينى 201107207064N1 و داراى مجوز اخلاق از شوراى دائ منطقهاى اخلاق در يزوهش دانشكاه علوم يزشكى كناباد است كه

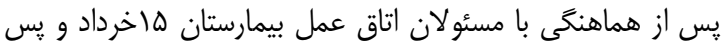

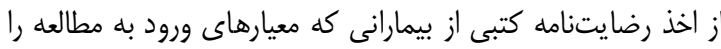

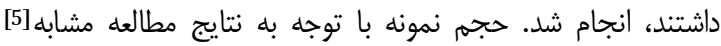

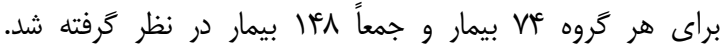

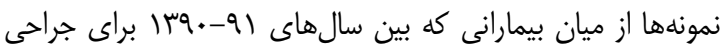
TURP به اتاق عمل بيمارستان هاخرداد كناباد مراجعه كرده بودند بلمروش نمونه كَيرى تصادفى ساده انتخاب شدند. افراد شركت كت كننده در تحقيق مردان غيرمعتاد با سن بالاى •ه سال با ASA (انجمن متخصصان بىهوشى آمريكا) كلاس دو، سابقه افزايش فشار خدال سيستميك كنترلشده و عدم وجود اختلالات انعقادى بودند. معيارهاى خروج از مطالعه نيز شامل؛ عدم تمايل به ادامه تحقيق،

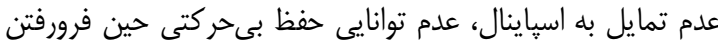

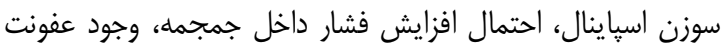
يوست يا بافت نرم ناحيه اسياينال، وجود هييولمى شديد، هرنى إنى إنى ديسكال لومبار يا سابقه جراحى ستون مهرههاى لومبار و نياز به نهان ترانسفوزيون حين عمل جراحى بود.

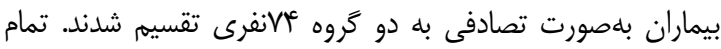

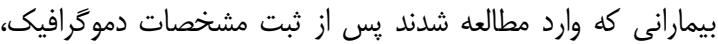

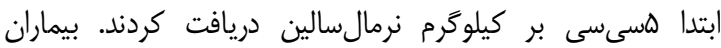
مانيتورينگ كامل (فشار خون، ضربان قلب، الكتروكارديوكرام و

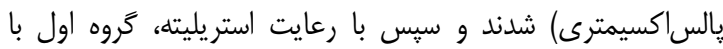

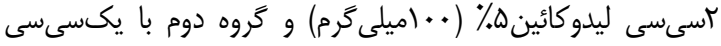

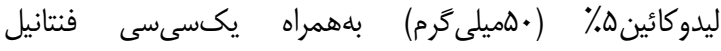

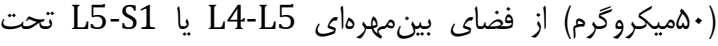

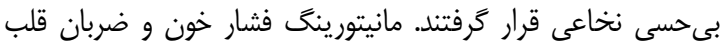


كافى ايجاد كرد، در حالى كه عملكرد حركتى دستنخورده بود [12].

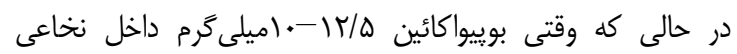

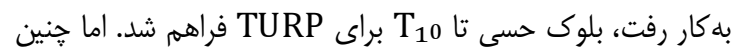

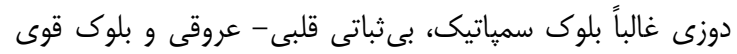

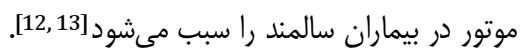

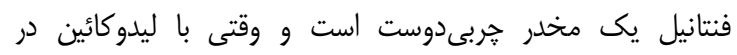

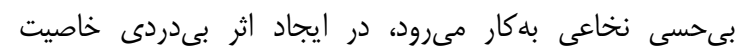

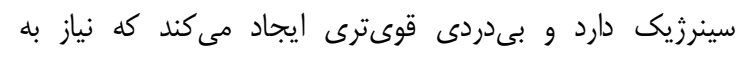

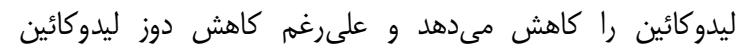

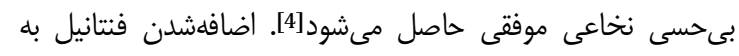

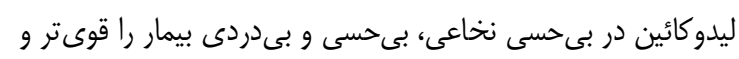

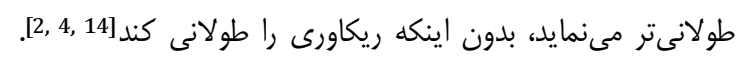

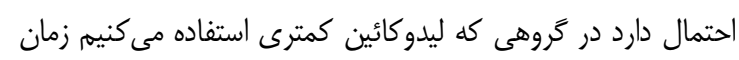
ريكاورى كوتاهتر باشد[4].

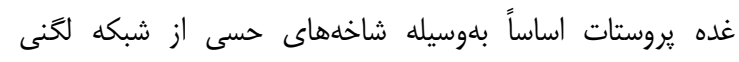

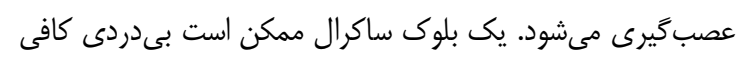

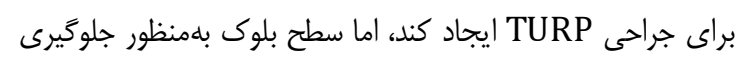

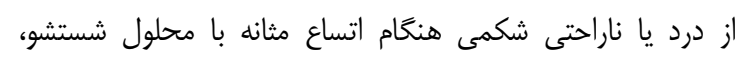

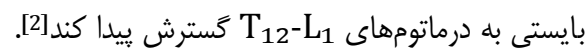

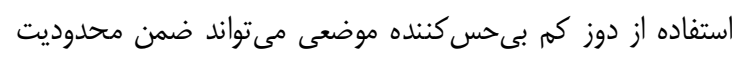

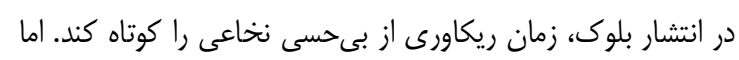

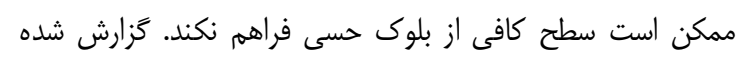

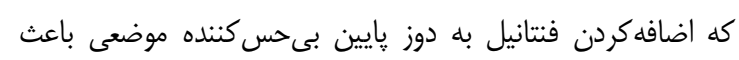

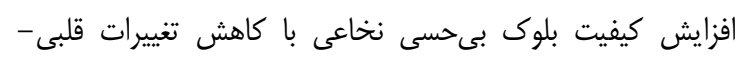

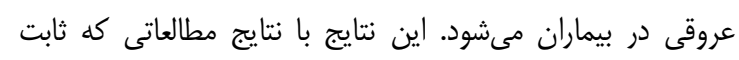

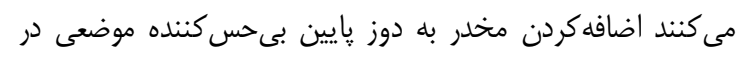

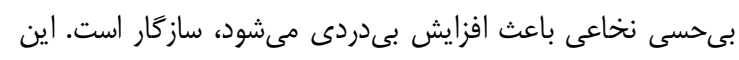

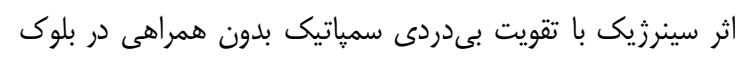

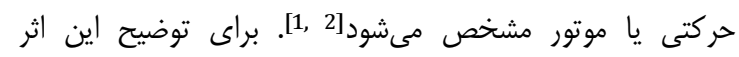

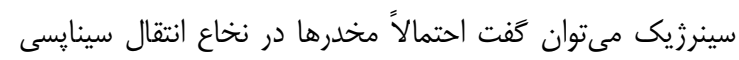

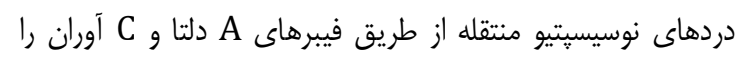

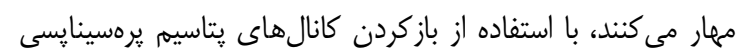

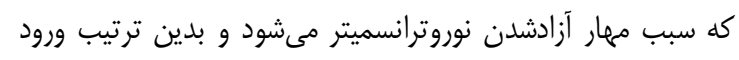

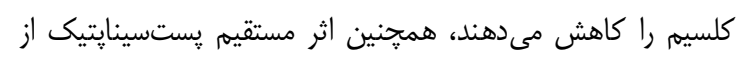

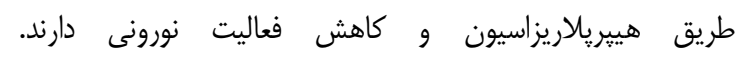

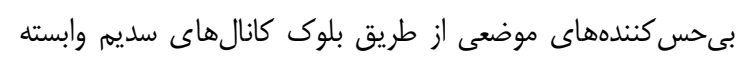

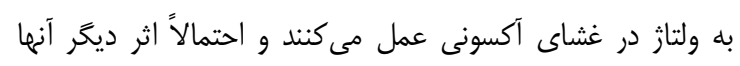

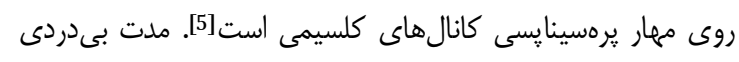

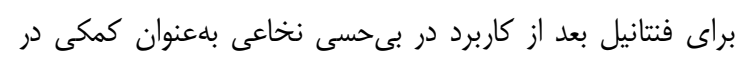

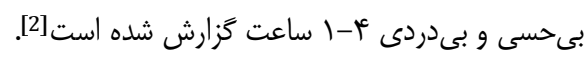

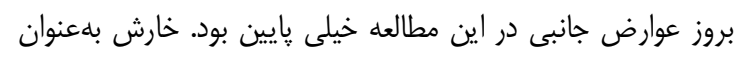

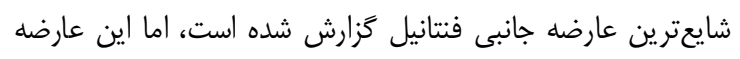

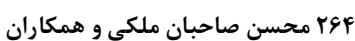

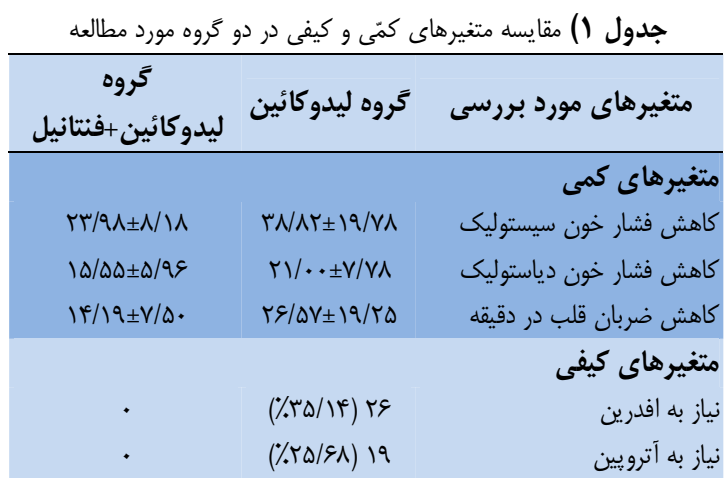

\section{بحث}

در اين مطالعه در كروه ليدوكائين+فنتانيل ضمن ايجاد بـ بحسى و

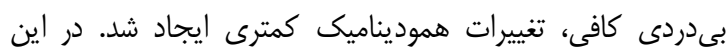
كروه ميزان كاهش در فشار خون تيرن سيستوليك، دياستوليك و تعداد

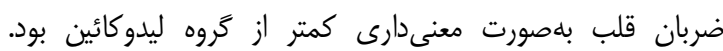

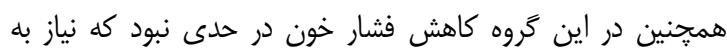

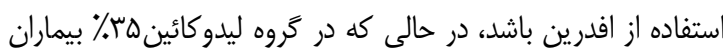

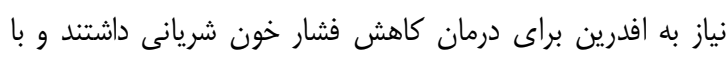

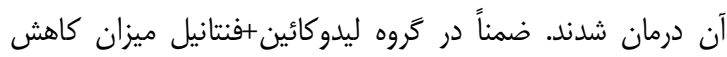

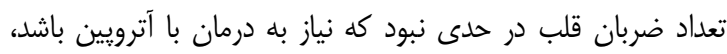

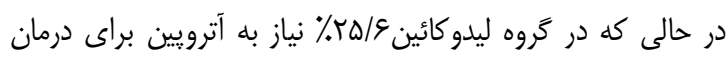
براديكاردى داشتند و با آن درمان شداند.

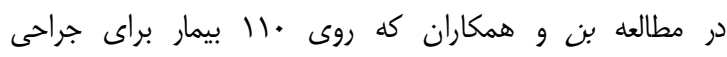

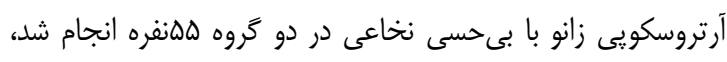

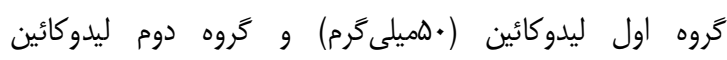

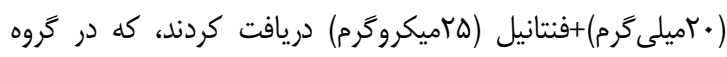

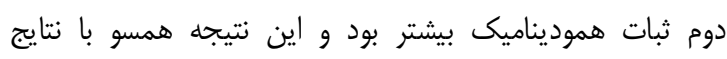
مطالعه حاضر است] [4].

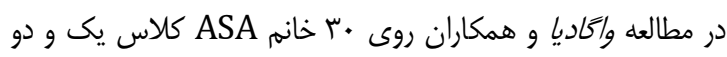

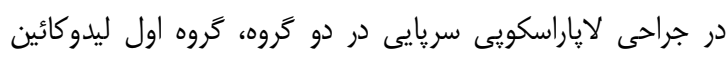
(هاميلى

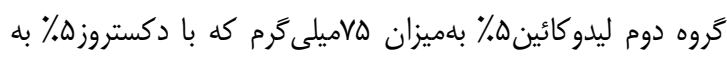

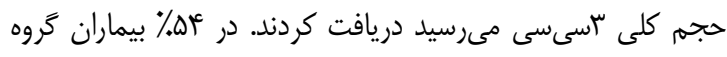

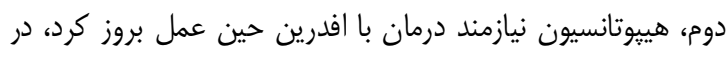

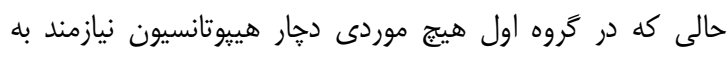

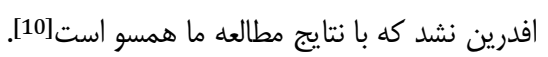

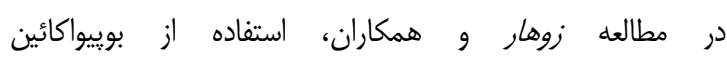
(أميلى

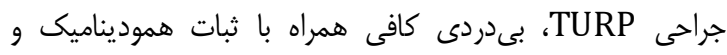

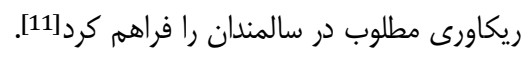

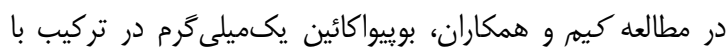

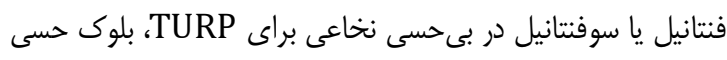




\section{نتيجه كيرى}

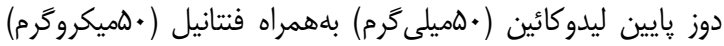

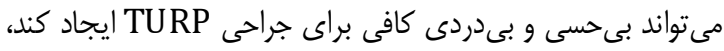

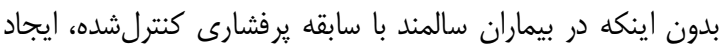

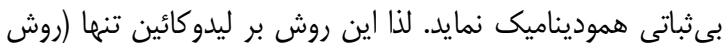
مرسوم) در اين گروه از بيماران برترى داردي لماني

تشكر و قدردانى: از كليه مسئولان، يزشكان و كاركنان اتاق عمل بيمارستان هاخرداد و معاونت يزوهشى دانشگاه علوم يزشكى كَاباد كه در اجراى اين طرح تحقيقانى همكارى لازي لازم را داشتند

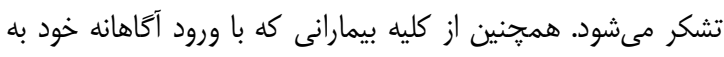

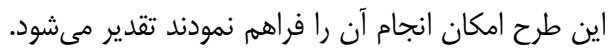

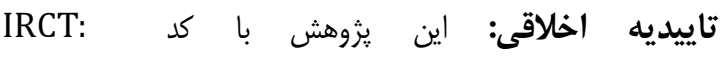
201107207064N1 داراى مجوز اخلاق از شوراى منطقهاى اخلاق در يُزوهش دانشعاه علوم :زشكى گَناباد است. تعارض منافع: موردى از طرف نويسندكان بيان نشده است. منابع مالى: اين مقاله مصوب شوراى يثوهشى دانشگاه علوم يزشكى كَناباد بوده و از طرف اين شورا تامين مالى شده است.

\section{منابع}

1- Miller RD. Anesthesia book. 7th edition. London: Churchill Livingstone; 2015. pp. 873-2986.

2- Kim SY, Cho JE, Hong JY, Koo BN, Kim JM, Kil HK. Comparison of intrathecal fentanyl and sufentanil in lowdose dilute bupivacaine spinal anaesthesia for transurethral prostatectomy. $\mathrm{Br} \mathrm{J}$ Anaesth. 2009;103(5):750-4.

3- Hines RL, Marschall K. Stoelting's anesthesia and coexisting disease. $6^{\text {th }}$ edition. Canada: Elsevier; 2012. p. 353.

4- Ben-David B, Maryanovsky M, Gurevitch A, Lucyk C, Solosko D, Frankel R, et al. A comparison of minidose lidocaine-fentanyl and conventional-dose lidocaine spinal anesthesia. Anesth Analg. 2000;91(4):865-70.

5- Ben-David B, Solomon E, Levin H, Admoni H, Goldik Z. Intrathecal fentanyl with small-dose dilute bupivacaine: better anesthesia without prolonging recovery. Anesth Analg. 1997;85(3):560-5.

6- Maves TJ, Gebhart GF. Antinociceptive synergy between intrathecal morphine and lidocaine during visceral and somatic nociception in the rat. Anesthesiol. 1992;76(1):91-9.

7- Wang C, Chakrabarti MK, Whitwam JG. Specific enhancement by fentanyl of the effects of intrathecal bupivacaine on nociceptive afferent but not on sympathetic efferent pathways in dogs. Anesthesiol. 1993;79(4):766-73.

8- Penning JP, Yaksh TL. Interaction of intrathecal morphine with bupivacaine and lidocaine in the rat. Anesthesiol. 1992;77(6):1186-2000.

9- Pöpping DM, Elia $N$, Wenk $M$, Tramèr MR. Combination of a reduced dose of an intrathecal local anesthetic with a small dose of an opioid: A meta-

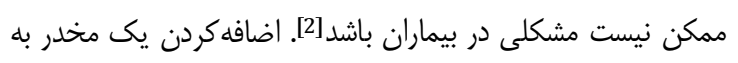

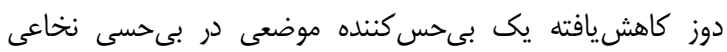

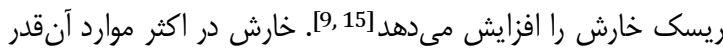

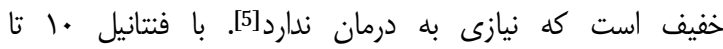

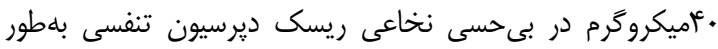
قابل ملاحظهاى افزايش نمى يابد[15].

فنتانيل يك آكونيست مخدر نيمهصناعى با تمايل قوى برى براى محل

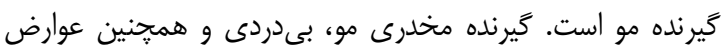
جانبى مخدرها از قبيل تهوع، سديشن و ديرسيون تنفسى رئ را ايجاد

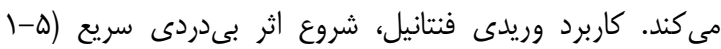

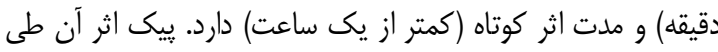

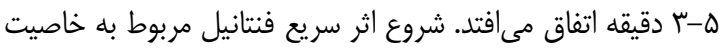

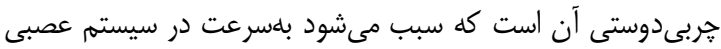

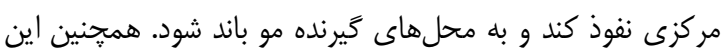
خاصيت سبب مىشود دارو بلهرعت از خون به ديخر بافتهاى بدن

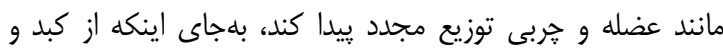
كليه دفع شود و اين سبب كوتاهشدن مدت اثر آن مىشود. بهخاطر بهري

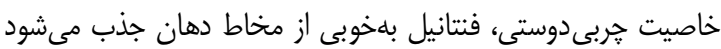

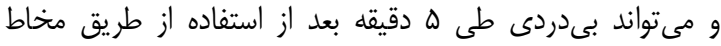

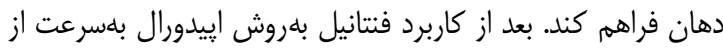

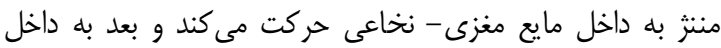
نخاع براى باند به محلهاى گيرنده مخدرى وارد مىشود [11].

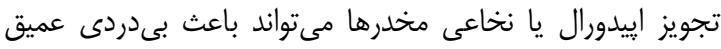

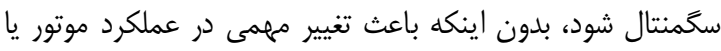

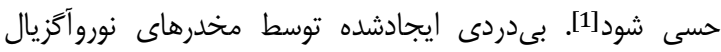

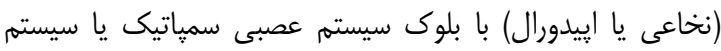

عضلات اسكلتى يا ازبينرفتن درى حس عمقى بـ همراه نيست [11].

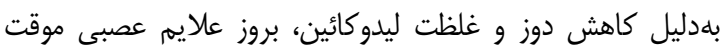
بعد از ليدوكائين نخاعى كاهش مى يابد[4]. وقتى مخدرها بلهصورت نخاعى به كار مىروند، خارش يك عارضه شايع است [11].

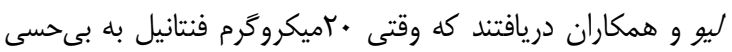

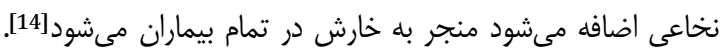
در مطالعه كوسنيمى و همكاران، خارش شايعترين عارضه جانبى بود، اما خارش بلهوبى تحمل شد و هيج كدام نياز به درمان

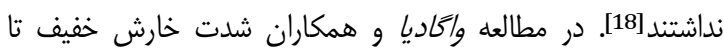

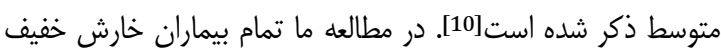
در ناحيه صورت ذكر كردند، ولى نيازى به درمان نبود. در نتيجه دوز

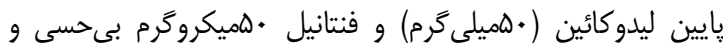

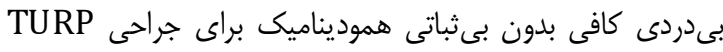

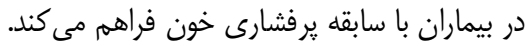

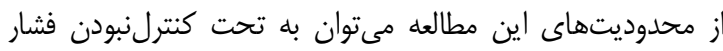
خون بيماران اشاره نمود. 
14- Liu S, Chiu AA, Carpenter RL, Mulroy MF, Allen HW, Neal JM, et al. Fentanyl prolongs lidocaine spinal anesthesia without prolonging recovery. Anesth Analg. 1995;80(4):730-4.

15- Pöpping DM, Elia N, Marret E, Wenk $M$, Tramèr MR. Opioids added to local anesthetics for single-shot intrathecal anesthesia in patients undergoing minor surgery: A meta-analysis of randomized trials. Pain. 2012;153(4):784-93.

16- Pasero C. Fentanyl for acute pain management. J Peri Anesth Nurs. 2005;20(4):279-84.

17- Hamber EA, Viscomi CM. Intrathecal lipophilic opioids as adjuncts to surgical spinal anesthesia. Reg Anesth Pain Med. 1999;24(3):255-63.

18- Kuusniemi KS1, Pihlajamäki KK, Pitkänen MT, Helenius HY, Kirvelä OA. The use of bupivacaine and fentanyl for spinal anesthesia for urologic surgery. Anesth Anal. 2000;91(6):1452-6.
99 ب9 محسن صاحبان ملكى و همكاران

analysis of randomized trials. Pain. 2013;154(8):1383-90. 10- Vaghadia H, Mcleod DH, Mitchell GW, Merrick PM, Chilvers CR. Small-dose hypobaric lidocaine-fentanyl spinal anesthesia for short duration outpatient laparoscopy. I. A randomized comparison with conventional dose hyperbaric lidocaine. Anesth Analg. 1997;84(1):59-64.

11- Zohar E, Noga Y, Rislick U, Leibovitch I, Fredman B. Intrathecal anesthesia for elderly patients undergoing short transurethral procedures: a dose-finding study. Anesth Analg. 2007;104(3):552-4.

12- Kim NY, Kim SY, Ju HM, Kil HK. Selective spinal anesthesia using $1 \mathrm{mg}$ of bupivacaine with opioid in elderly patients for transurethral resection of prostate. Yonsei Med J. 2015;56(2):535-42.

13- Vaghadia H. Spinal anesthesia for outpatients: controversies and new techniques. Can J Anaesth. 1998;45(Suppl 1):R64-75 